\title{
Formação docente aliada aos novos recursos das TICs
}

Silvia de Castro Bertagnolli

silviacb@uniritter.edu.br

Lauren Aparecida Barcelos Sanches

lauren@uniritter.edu.br

Michele de Mattos Kreme

michele_kreme@uniritter.edu.br

Adriana Sadowski de Souza

adriana_souza@uniritter.edu.br

Angela Maria da Silva

angela_silva@uniritter.edu.br

Centro Universitário Ritter dos Reis - UniRitter

Rua Orfanatrófio, 555 - Alto Teresópolis - Porto Alegre - RS - CEP 90840-440

\section{RESUMO}

A formação de docentes para a Educação a Distância é um fator essencial para o sucesso desta modalidade de Ensino. Logo, é importante analisar e conhecer as competências e habilidades necessárias para os professores em um contexto de Ensino Superior, incluindo o conhecimento do Ambiente Virtual de Aprendizagem (AVA). Este artigo apresenta uma reflexão sobre os elementos necessários para o desenvolvimento de uma formação docente aliada aos recursos das Tecnologias da Informação e Comunicação (TICs), e como elas podem facilitar o processo de ensinoaprendizagem. Para tanto, serão apresentados os pressupostos teóricos necessários para uma formação pedagógica, tecnológica e sua união para a produção do saber.

Palavras-chave: formação docente, tecnologias da informação e comunicação, ambiente virtual de aprendizagem, competências e habilidades.

\section{Teacher training coupled with the new features of ICTs}

\begin{abstract}
The training of teachers for distance education is an essential factor for the success of this modality of education. It is therefore important to analyze and understand the skills and abilities needed by teachers in a context of higher education, including knowledge of the Virtual Learning Environment (VLE). This article presents a reflection on the elements necessary to develop a teacher training combined resources of Information Technology and Communication (ICTs) and how they can facilitate the teachinglearning. For this, we present the theoretical assumptions required for a teacher training, technological and her marriage to the production of knowledge.
\end{abstract}

Keywords: teacher training, information technologies and communication, virtual learning environment, skills and abilities. 


\section{INTRODUÇÃO}

A oferta de cursos de Graduação total ou parcialmente a distância tem crescido muito nos últimos anos. $\mathrm{Na}$ modalidade semipresencial, que se caracteriza por ser parcialmente a distância, o desenvolvimento da aprendizagem ocorre parte em encontros presenciais e parte em encontros a distância. Esta modalidade de ensino utiliza a Portaria do MEC n . 4.059/2004 que estabelece que cursos de Graduação podem usar até $20 \%$ de sua carga horária total para desenvolver atividades a distância.

Nesse contexto, o UniRitter (Centro Universitário Ritter dos Reis) passou a utilizar a modalidade semipresencial em seus cursos de Graduação (Licenciaturas em Pedagogia e Letras, e nos Bacharelados em Administração, Arquitetura, Direito e Sistemas de Informação). Essa modalidade de ensino passou a ser utilizada com o intuito de oferecer aos acadêmicos novas formas de aprendizagem, diferentes das tradicionais.

Espera-se que o uso de Tecnologias da Informação e Comunicação na Educação (TICs), por alunos de Graduação, possibilite o desenvolvimento de outras competências e habilidades, além das já previstas pelas grades curriculares tradicionais.

Devido à crescente necessidade de permanente qualificação do processo de ensinar e aprender, o UniRitter desenvolveu o Programa Institucional de Educação a Distância/EaD, o qual se encontra vinculado à Pró-Reitoria de Ensino, desde o ano de 2003. O objetivo principal deste programa é possibilitar a constante qualificação docente no que diz respeito a aspectos pedagógicos e tecnológicos, e ainda oportunizar a auto-aprendizagem com a mediação de recursos didáticos sistematicamente organizados.

Destaca-se que a Instituição adota duas modalidades de ensino: (i) a semipresencial, que utiliza o percentual acima referido para alguns de seus cursos de Graduação, e a (ii) totalmente presencial, composta por disciplinas que podem, ou não, utilizar o Sistema Institucional Virtual de EaD para proporcionar uma maior interação entre acadêmicos/acadêmicos, e acadêmicos/ docentes.

Para viabilizar uma maior comunicação e interação entre os envolvidos é necessário o desenvolvimento de materiais didáticos diferenciados, e os professores devem estar devidamente qualificados e confiantes no uso do Ambiente Virtual de Aprendizagem (AVA).

Ainda nesse contexto, observa-se que os docentes envolvidos no processo de ensino/aprendizagem precisam perceber a importância de aliar a prática pedagógica com a tecnologia, a fim de incorporar um maior dinamismo às aulas, trazendo novas propostas de aprendizagem aos alunos, permitindo uma maior flexibilidade na aquisição do conhecimento e um aprendizado mais autônomo. Mas, para que isso ocorra, é preciso que a Instituição ofereça uma formação docente consistente, apresentando todos os elementos que dêem condições aos professores de mudarem a sua postura diante dos conteúdos abordados com os alunos.

Com o intuito de atingir o objetivo acima enumerado, verifica-se que é importante que o docente domine o Ambiente Virtual de Aprendizagem (AVA) utilizado pela Instituição. Além de conhecer a importância das TICs no ensino atual e as relações existentes com as práticas pedagógicas adotadas.

Destaca-se ainda que, o material disponibilizado desenvolvido por professores, e posteriormente disponibilizado no Sistema Institucional Virtual de EaD, deve estar em 
consonância com a lei de direitos autorais, Lei no .9610 de 19 de fevereiro de 1998, pois o incentivo pela autoria deve partir do professor.

Desse modo, o objetivo do presente artigo consiste em apresentar uma reflexão sobre os elementos necessários para o desenvolvimento de uma formação docente aliada aos recursos das Tecnologias da Informação e Comunicação (TICs), e como elas podem facilitar o processo de ensino-aprendizagem.

O artigo prossegue apresentando, na seção 2, a importância das TICs na formação superior; na seção 3, um referencial teórico sobre AVAs; na seção 4 são abordadas as competências e habilidades necessárias para um docente na modalidade a distância; na seção 5 são apresentados alguns aspectos relacionados com formação docente; e, finalmente na seção 6 são descritas algumas conclusões.

\section{A IMPORTÂNCIA DAS TICs NA FORMAÇÃO SUPERIOR}

A Educação a Distância utiliza um processo de ensino-aprendizagem, onde professores e alunos podem estar separados espacial e temporalmente, mas interligados por meios de tecnologias, como, por exemplo, a Internet. Nesse sentido, o uso das Tecnologias da Informação e Comunicação pode ser usufruído nos diferentes níveis de ensino, mas, atualmente, o foco está direcionado para o Ensino Superior, tanto a nível de Graduação quanto a nível de Pós-Graduação.

As TICs são vistas como um conjunto de recursos tecnológicos (como, por exemplo, computadores pessoais, telefonia móvel, Internet, e-mails, entre outros) que proporcionam um processo de ensino e aprendizagem mais autônomo, visando uma busca maior do conhecimento (Graça, 2007).

Nesse sentido, observa-se que as TICs desempenham um papel cada vez mais importante na $\mathrm{EaD}$, pois a Informação e a Comunicação são fatores definitivos para o processo da construção do conhecimento, porque é através delas que ocorrem as trocas entre os envolvidos. Já as tecnologias são consideradas o meio para estabelecer este canal de comunicação e interação entre os participantes da EaD (Graça, 2007).

Embora os envolvidos pertençam ao ensino superior é possível encontrar muitas resistências com relação ao uso de TICs, pois alguns professores não acreditam na qualidade desta modalidade de ensino; muitos docentes, assim como muitos acadêmicos, acreditam que o modelo tradicional onde a relação pessoal se estabelece é o melhor. Alguns argumentam que a "distância" não tem como substituir o "contato presencial" e que as possibilidades de trocas são maiores quando todos os envolvidos estão fisicamente em um mesmo local.

A idéia das TICs é permitir a construção de espaços que a sala de aula não oportuniza, e o estabelecimento de relações que presencialmente não ocorreriam, por diversos motivos (timidez, falta de tempo "presencial", a falta de percepção de interesses relacionados, entre outros).

Outro aspecto importante com relação às TICs é a capacidade de desenvolver outras competências e habilidades, além das já previstas pelas grades curriculares tradicionais. Elas oportunizam ao acadêmico uma formação diferenciada que contribuirá para que ele tenha condições de estar enfrentando desafios.

Na Educação a Distância o uso mais presente das TICs ocorre através dos AVAs, como descreve a próxima seção.

\section{AMBIENTES VIRTUAIS DE APRENDIZAGEM}


Os Ambientes Virtuais de Aprendizagem são utilizados para mediar toda a comunicação entre os envolvidos no processo de construção dinâmica do conhecimento, seja o processo voltado para a Educação a Distância ou, até mesmo, para a presencial.

Os AVAs viabilizam uma aprendizagem mais dinâmica, baseada na pesquisa e na constante busca pelo conhecimento (Bertagnolli e Silveira, 2007). Algumas instituições estão apenas replicando as aulas presenciais através de seus ambientes de aprendizagem, porém isto pode ser considerado como uma "interação virtual fria", visto que os professores apenas transferem a rotina da sala de aula para o ambiente virtual. Para esse tipo de comunicação qualquer ambiente serve, pois não há dinamicidade e troca de conhecimento entre os envolvidos.

A visão adequada de Educação a Distância é aquela que parte de um aspecto individual para um fundamentado no grupo dos indivíduos que compõe uma turma. Com ela, os alunos interagem entre si e com o professor para complementar algo, até então, desconhecido (Moran, 2000).

Assim, esses ambientes ampliam as possibilidades de interação entre aluno e professor, pois eles são essenciais para a organização das idéias, do conhecimento e oportunizam ao aluno uma maior autonomia com relação a sua aprendizagem (Neto, 2004).

Com o intuito de realizar a gestão do processo de aprendizagem, utilizando a web como canal de comunicação, surgem diversos AVAs, que podem ser denominados de "salas de aula virtual" (Mehlecke e Tarouco, 2003).

Essa sala de aula é chamada de virtual, porque o aluno está livre para buscar seu conhecimento, sem depender, exclusivamente, de um professor. Na verdade, o aluno sai da condição de apenas receber conhecimento, ele passa para a situação de investigador/pesquisador que não possui como foco de sua aprendizagem a sala de aula presencial (Mehlecke e Tarouco, 2003).

Pode-se, assim, afirmar que um dos principais fatores da aprendizagem em Educação a Distância é o AVA e suas ferramentas, pois ele servirá como mediador entre professor e aluno no processo de aquisição do conhecimento, simulando uma sala de aula no ambiente virtual, possibilitando a interação.

Devido a este fato, é importante ter um ambiente com diversidade de ferramentas interativas, mas ainda assim é importante lembrar que os alunos não conseguirão construir seus conhecimentos sozinhos, pois o conhecimento deve ser construído entre alunos e professores durante o processo de aprendizagem, e não passado de professores a alunos (Mehlecke e Tarouco, 2003).

Atualmente, é possível encontrar na literatura um número expressivo de AVAs como, por exemplo: Moodle, AulaNet, TelEduc, Dokeos e NAVi, entre outros. Porém, após realizar um estudo comparativo entre esses ambientes percebeu-se que o ambiente Moodle é um ambiente composto por uma diversidade de ferramentas, que podem promover a comunicação assíncrona e síncrona. Ele utiliza uma linguagem dinâmica e atual, pois além das ferramentas tradicionais de interação disponibiliza o uso de blogs e wikis, que permitem estabelecer redes sociais. Outro diferencial é a possibilidade de, através de plugins, incorporar funcionalidades que ampliam o poder de interação do ambiente.

Este ambiente ainda apresenta algumas vantagens, tais como: sistema aberto (que permite que os usuários realizem alterações, adaptações e correções), interações sócio-construtivistas (a existência de um grupo social que constrói coisas para os outros) e a construção de comunidades virtuais (Reis, 2007); além de permitir a integração de diferentes mídias e recursos (Porfiro, 2008). 
Embora o ambiente virtual seja essencial para o desenvolvimento de ações em EaD, o comprometimento dos docentes com esta modalidade de ensino, também é fundamental. Logo, a próxima seção apresenta algumas competências e habilidades requeridas para os docentes de disciplinas semipresenciais ou a distância.

\section{DOCENTES: COMPETÊNCIAS E HABILIDADES}

Para que a EaD fosse desenvolvida utilizando alguns dos critérios de qualidade definidos pelo MEC o UniRitter desenvolveu o Programa Institucional de Educação a Distância/EaD. O foco deste programa é possibilitar a constante qualificação docente no que diz respeito a aspectos pedagógicos e tecnológicos, e ainda oportunizar a autoaprendizagem com a mediação de recursos didáticos sistematicamente organizados.

Para apoiar o desenvolvimento deste Programa foi criado o NeaD - Núcleo de Apoio à Educação a Distância, que é composto por uma equipe multidisciplinar, com conhecimentos técnicos em Computação e pedagógicos, e que dispõe de equipamentos e de softwares específicos para a criação de materiais didáticos para a EaD.

O principal objetivo deste núcleo é desenvolver atividades de acompanhamento e formação dos docentes e discentes, organização de cursos de qualificação pedagógica em EaD e suporte/gerenciamento do AVA utilizado pela Instituição.

Essas atividades de qualificação são sugeridas por professores e pela própria Instituição, com o intuito de buscar um constante aperfeiçoamento no que diz respeito ao AVA utilizado e às praticas pedagógicas aplicadas às disciplinas.

Destaca-se que, neste tipo de modalidade o professor tem o papel de ser mediador do processo de ensino e aprendizagem. Além disso, ele precisa ser um integrador das competências objetivadas nas disciplinas. A motivação do aluno deve ser trabalhada pelo professor para que o seu trabalho tenha possibilidades de alcançar os objetivos. O professor deve acompanhar as atividades dos acadêmicos, incentivar a responsabilidade pelo construção do conhecimento, e fomentar no aluno a visão de que ele deve possuir autonomia e um perfil investigativo.

Sob esse aspecto, a Instituição utiliza a abordagem construtivista, segundo Vygotsky (1989), essa vê o aluno como construtor do seu conhecimento, mas que está inserido em uma sociedade, em uma determinada cultura que determinará o seu saber.

Nos últimos anos, ocorreram diversos avanços tecnológicos que tiveram impacto direto na educação. A inclusão das TICs impôs uma mudança no perfil dos docentes, que passaram a organizar suas atividades em sala de aula (presencial ou virtual) com o apoio da tecnologia.

Como essa mudança, o professor precisa ter conhecimentos e habilidades: técnicos, teórico/práticos, didáticos e comportamentais. Isso tudo leva a conclusão que os professores não podem ter apenas saberes, mas sim competências profissionais que vão além dos conteúdos que precisam ser ensinados, isto é, são necessárias competências e habilidades próprias para a modalidade EaD.

É de suma importância indicar o conceito de competências para um melhor entendimento. Para Perrenoud (2009) é:

"[..] a faculdade de mobilizar um conjunto de recursos cognitivos (saberes, capacidades, informações, etc.) para solucionar com pertinência e eficácia uma série de situações. Estão ligadas a contextos culturais, profissionais e condições sociais." 
Dessa forma, uma competência necessita de três elementos para que seja consistente: conhecimento, habilidade e atitudes. No contexto do Ensino Superior, é possível dizer que o professor passa a ser visto como uma pessoa que precisa criar meios de auxiliar o aluno a aprender. Em contrapartida, o aluno precisa se propor a aprender, ou seja, o esforço é de ambos os lados para que possa ocorrer a eficiência do ensino.

Na Educação a Distância isso ocorre com mais intensidade do que na Educação Presencial, pois o professor deve elaborar materiais didáticos dinâmicos, conhecer ferramentas que viabilizem o dinamismo e, ainda, ter um certo domínio sobre o AVA utilizado na EaD.

É muito importante abordar que o processo de aquisição do conhecimento ocorre ao longo da vida, no momento em que um indivíduo realiza alguma coisa e reflete sobre a mesma. Mas isso requer regras e aprendizado constante, isto é, conhecimento criativo e organização.

Segundo Konrath (2009) a aquisição das competências envolverá:

“[...] (1) o saber e o fazer, (2) a teoria e a prática e (3) os princípios e processo da tecnologia educacional. Neste sentido, as diferenças estão ligadas à questão de que as novas tecnologias é que dão suporte ao processo de ensino-aprendizagem, assim como proporcionam uma nova interação em termos de tempo e espaço com relação ao objeto de estudo/conhecimento."

É preciso focar que as habilidades precisam ser desenvolvidas com o intuito de buscar as competências. Essas podem ser conceituadas como a capacidade relacionada ao saber-fazer de forma física ou mental determinada atividade.

Para Moretto (2002), habilidades são exemplificadas como: "identificação de variáveis, compreensão de fenômenos, relacionamento de informações, análise de situações-problema, síntese, julgamento, correlação e manipulação".

A união desses dois conceitos permitirá que a Instituição tenha condições de desenvolver uma formação docente consistente e que busque a inovação a fim de prover benefícios aos docentes e discentes.

Mas, para que se tenha sucesso, é necessário analisar o perfil dos docentes da Instituição e as dificuldades encontradas na utilização das tecnologias, em especial do AVA. Com a experiência, percebe-se que é necessário que eles desenvolvam competências específicas, dependendo da sua área de atuação. Por exemplo, competências, pedagógicas, técnicas, comunicativas, gestão e de suporte social. A competência técnica acaba sendo a principal, pois, se o docente não domina o AVA utilizado, fica difícil propor atividades mais dinâmicas para os alunos.

\section{A FORMAÇÃO DOCENTE}

Sabe-se que, em um AVA, a mediação tecnológica passa a ser fator essencial no processo de construção das relações. Algumas pesquisas encontradas na literatura informam que o relacionamento estabelecido em um ambiente virtual, muitas vezes, pode ser mais intenso que em uma comunicação presencial. Conforme informa Soares (2003) "Acreditam, mesmo, que o fator comunicação - mais que os conteúdos transmitidos - é o que gera o conhecimento". 
A mediação pedagógica pode ser definida, segundo Masetto (2006, p.144) como: "[...] a atitude, o comportamento do professor que se coloca como um facilitador, incentivador ou motivador da aprendizagem que se apresenta com a disposição de ser uma ponte entre o aprendiz e sua aprendizagem [...]".

Nessa perspectiva, aprender acaba se tornando uma proposta partilhada. Todos os indivíduos envolvidos no processo de aprendizagem participam de forma muito importante para que ocorra o crescimento individual e do grupo. No momento em que a aprendizagem ocorre em um ambiente participativo, a experiência e o conhecimento de cada um é valorizado, lembrando-se que é preciso respeitar as diferenças.

Um ponto importante para ser abordado são as diretrizes curriculares nacionais (Parâmetros Curriculares Nacionais - PCNs). Segundo Garcia (2009) elas relacionam-se aos:

"[...] diferentes níveis de ensino e uma série de outros documentos oficiais referentes à educação no Brasil têm colocado - em consonância com uma tendência mundial - a necessidade de centrar o ensino e aprendizagem no desenvolvimento de competências e habilidades por parte do aluno, em lugar de centrá-lo no conteúdo conceitual. Isso implica uma mudança não pequena por parte da escola, que sem dúvida tem que ser preparada para ela."

Analisando o trabalho de Litwin (2001, p.10), percebe-se que os programas de Educação a Distância devem utilizar:

“[...] conteúdos atualizados e enfoques novos, identifica conceitos relevantes de um campo e suscita ou desenvolve polêmicas e reflexões. Um bom programa comporta um corpo docente preocupado com a compreensão dos estudantes."

Porém, identifica-se que há uma "distância" muito grande entre as práticas pedagógicas aplicadas em salas de aula presenciais e que devem ser reformuladas para que possam ser aplicadas nas modalidades a distância e semipresencial.

Segundo Gatti (2009), verifica-se que as condições de formação dos professores ainda estão distantes de serem consideradas satisfatórias. Os currículos escolares acabam por serem estruturados segundo as questões relacionadas às práticas profissionais, com os seus fundamentos metodológicos e formas de trabalhar na sua sala de aula. Porém, é esquecida a relação entre teoria e prática que precisa ser estabelecida com os futuros professores, isto é, as competências e habilidades que precisam ser abordadas para que esses profissionais possam inovar as suas práticas.

Devido à exigência legal (estabelecida pela lei 9394/96) de formação em nível superior para todos os professores, o foco da formação inicial docente está centrado integralmente para o ensino superior. Dessa forma, é de extrema importância, fornecer qualificações docentes para melhor preparar os professores que atuarão em sala de aula (Gatti, 2009).

Dessa forma, é de suma importância relacionar a teoria e a prática em um cenário no qual o indivíduo aprenda a pensar e a fazer, estabelecer vínculos e produzir conhecimento. As Instituições de Ensino Superior, principalmente, precisam respeitar as diferenças dos alunos, bem como os seus saberes. Já os professores são responsáveis por gerar reflexões, estabelecendo relacionamentos teórico-práticos. Essa afirmativa é reforçada pelas argumentações de Gatti (2009):

“ os profissionais de ensino constituem o terceiro grupo ocupacional mais numeroso, apenas precedidos pelos escriturários e trabalhadores do 
setor de serviços, e, entre estes, o que possui o mais alto nível de instrução (nível médio e superior), bem como as características homogêneas, em vista da forte regulamentação que cerca o exercício da profissão. Os dados, para termos comparativos, são claros: escriturários representam $15,2 \%$ da força de trabalho; empregados do setor de serviços 14,9\%; docentes 8,4\%; empregados da construção civil e indústrias extrativas 4\%".

Para poder estruturar uma formação docente, é preciso entender os aspectos pedagógicos, tecnológicos e as relações existentes entre eles.

$\mathrm{Na}$ formação pedagógica, durante muito tempo, acreditava-se que, quando a Graduação terminava, o profissional estava apto para atuar na sua área pelo resto da vida. Porém, o advento do século XXI trouxe a necessidade de redefinir muitos aspectos até então considerados inquestionáveis.

A partir desta realidade, torna-se essencial uma renovação do saber fazer educativo, tanto no que se refere à atualização em relação aos conhecimentos específicos das disciplinas pelas quais o professor é responsável, como, também, pela atenção às novas tecnologias voltadas para melhoria na disseminação e qualidade do ensino.

Segundo Zagaroza (1999), alguns fatores tornam-se determinantes para a modificação do papel do professor na sociedade, como o aparecimento de novos agentes de socialização, como, por exemplo, os meios de comunicação e o consumo cultural de massa.

Esta nova diversidade e imprevisibilidade social, cultural, educativa e tecnológica, geram diferenças que obrigatoriamente terão de assumir uma profunda reflexão sobre as práticas, os conhecimentos e as experiências educacionais, visto que, o professor não é mais o detentor ou fonte exclusiva de informação e conhecimento. Neste novo cenário educacional, a atualização docente se apresenta em um sentido contínuo de aprendizagem associado, que contextualiza tais reflexões com a inserção de novas tecnologias ao processo educativo.

Nessa perspectiva, as tecnologias digitais abrem "janelas" de comunicação com o mundo, formando alunos, atualizando professores, ao mesmo tempo em que expande diferentes interações, uma vez que, permite que estes ultrapassem os muros de espaços formais de educação.

Nesse contexto a Educação a Distância, permite que as tecnologias atuem vencendo distâncias entre educadores e educandos e entre eles e o conhecimento, a partir de estratégias pedagógicas eficientes. Somando a tudo isso, a EaD viabiliza o tipo de interação social entre alunos e professores que supera a "distância social", bem como, a "distância geográfica".

\section{CONCLUSÕES}

O trabalho, apresentando neste contexto, resume os elementos necessários para que se tenha uma formação docente aliada aos novos recursos das TICs.

A modalidade de ensino semipresencial tem incorporado uma mudança nos conceitos até hoje vivenciados, porque as TICs têm transformado a produção e a socialização dos saberes tanto para alunos quanto para professores. $\mathrm{O}$ intuito é buscar uma melhoria na qualidade da educação e à valorização da profissão docente.

Conforme os estudos realizados por Bertagnolli (2008), foi apontado pelos acadêmicos do UniRitter, como um diferencial desta modalidade, a possibilidade de realizar ora encontros virtuais ora encontros presenciais. O objetivo dessa modalidade é 
que os professores consigam motivar os alunos na busca e construção de conhecimentos no ambiente virtual.

Além disso, é possível perceber que a EaD do UniRitter está alicerçada no que há de melhor no mercado. Agora, a missão é atuar, ainda mais, como facilitadores deste processo, minimizando erros e entendimentos quanto aos sistemas, seus recursos e oferecer formações docentes de qualidade para permitir maior integração das práticas pedagógicas com as tecnológicas.

Verificou-se que, para a estruturação de uma formação docente consistente, é importante que o professor domine as TICs utilizadas pela Instituição, estando diretamente relacionado ao seu AVA. Para isso, o desenvolvimento de competências e habilidades para essa nova realidade de ensino é, extremamente, necessária. Assim como a relação existente entre pedagogia e tecnologia em uma formação.

\section{Referências}

BERTAGNOLLI, S. C. et.al.. Potencialidades e Desafios da Modalidade Semipresencial. 2008.

BERTAGNOLLI, Silvia; SILVEIRA, Sidnei Renato. Modalidade de Ensino Semipresencial como Forma de Qualificar a Aprendizagem no Curso de Sistemas de Informação do UniRitter. WEI Tchê - Workshop de Educação em Informática. Torres-RS: ULBRA, 2007.

GARCIA, L. A. M. Competências e Habilidades: você sabe lidar com isso? Disponível em: < http://www.centrorefeducacional.com.br/habicompv.htm>. Acesso em: 29 out. 2009.

GATTI, B. \& BARRETTO, E. S. de S. Professores no Brasil: impasses e desafios. Brasília: Unesco, 2009.

GRAÇA, A. Importância das TIC na Sociedade Actual. 2007. Disponível em: < http://www.notapositiva.com/trab_estudantes/trab_estudantes/tic/10importanctic.htm>. Acesso em 22 out. 2009.

KONRATH, M. L. P., TAROUCO, L. M. R., BEHAR, P. A. Competências: Desafios para alunos, professores $\mathrm{e}$ tutores da EaD. Disponível em: < http://www.cinted.ufrgs.br/renote/jul2009/artigos/3a_mary.pdf $>$. Acesso em: 26 out. 2009.

LITWIN, E. Educação a Distância: temas para o debate de uma nova agenda educativa. Porto Alegre: Artmed, 2001.

MASETTO, M T. Mediação pedagógica e o uso de tecnologia. In: MORAN, J. M., MASETTO, M. T.; BEHRENS, M. A. Novas Tecnologias e mediação pedagógica. Campinas: Papirus, 2006.

MEHLECKE, Q. T. C.; TAROUCO, L. M. Ambientes de Suporte para Educação a Distância: a mediação para aprendizagem cooperativa. Revista Novas Tecnologias na Educação, v. 1, n. 1, Fevereiro, 2003. Disponível em: $<$ http://www.cinted.ufrgs.br/renote/fev2003/artigos/querte_ambientes.pdf>. Acesso em: maio, 2007. 
MORAN, J. M. Ensino e Aprendizagem Inovadores com Tecnologia. Informática na Educação: Teoria \& Prática. Programa de Pós-Graduação em Informática na Educação. v. 3, setembro, 2000. p. 137-144. Porto Alegre: UFRGS/PPGIE.

MORETTO, V. Construtivismo, a produção do conhecimento em aula. Rio de Janeiro: DP\&A, 2002.

NETO, A. S. Comunicação e interação em ambientes de aprendizagem presenciais e virtuais. 2004. Disponível em: <http://fgsnet.nova.edu/cread2/creadarticlesearch/>. Acesso em: maio, 2007.

PERRENOUD. Dez novas competências para ensinar. Porto Alegre, Artes Médicas, 1999. Revista Nova Escola. Edições diversas.

PORFIRO, R. M. Uma ferramenta para gestão de grupos por perfil de alunos no ambiente Moodle. PUCRS, 2008. Disponível em: <http://www.scribd.com/doc/4605923/Estudando-o-moodle>. Acesso em: 01 jun. 2009.

REIS, C. B. Moodle. 2007. Disponível em:

$<$ http://claudiobarbosa.wordpress.com/2007/10/22/moodle-claroline-dokeos-claudiobarbosa/>. Acesso em 07 jun. 2009.

SOARES, I. de O. EAD como prática educomunicativa: emoção e racionalidade operativa. Disponível em: <http://www.usp.br/nce/wcp/arq/textos/3.pdf>. Acesso em: 27 out. 2009.

VYGOTSKY, L. A Formação Social da Mente. São Paulo: Martins Fontes, 1989.

ZARAGOZA, J. M. O Mal Estar Docente. São Paulo: EDUSC, 1999. 